\title{
Printing technology on textile fibers: Review
}

\author{
M El-Kashouti, Shimaa Elhadad*, Kawther Abdel-Zaher \\ Dyeing, Printing and Auxiliaries Department, Textile Industries Research Division, \\ National Research Centre, Cairo 12622, Egypt
}

\begin{abstract}
PPLICATION of the paste containing the dyes to the required areas on the fabrics is designated as direct printing, consequently dyeing and steaming followed by washing to remove any residues. In pigment printing, the pigments and cured binder adhere to fabric surface with the cured binder film. No further treatment is required. Direct printing is considered the most important printing. Fibers have been defined by the textile institute as units of matter which are characterized by fineness flexibility and high ratio of length to thickness. Fibers are the basic unit from which all textile materials are made. Textile goods are manufactured from fibrous material which may be either of natural or man-made origin.
\end{abstract}

Keywords: Printing; Textiles; Colorfastness

\section{Textiles Fibers}

There are two types of textile fibers usually classified as follows:

\section{Natural Fibers}

Natural fibers are divided in three groups: vegetable fibers (cotton, flax, hemp, kenaf, sisal and other), animal or proteinic (wool, silk), and non-organic or mineral fibers (asbestos) [1-4].

\section{Cotton Fibers:}

Cotton is the oldest and the most important of textile fibers. It has been used for thousands of years [5]. The fiber properties are determined by its chemical composition and structure [4].The approximate composition of raw cotton is given in Table 1 [6].

\section{Chemical structure:}

Cellulose is a linear natural polymer constructed from the condensation of $\beta$-glucose molecules linked together through e s1 and 4 positions [7, 8]. The chemical structure of cellulose can be represented as shown in Figure 2.

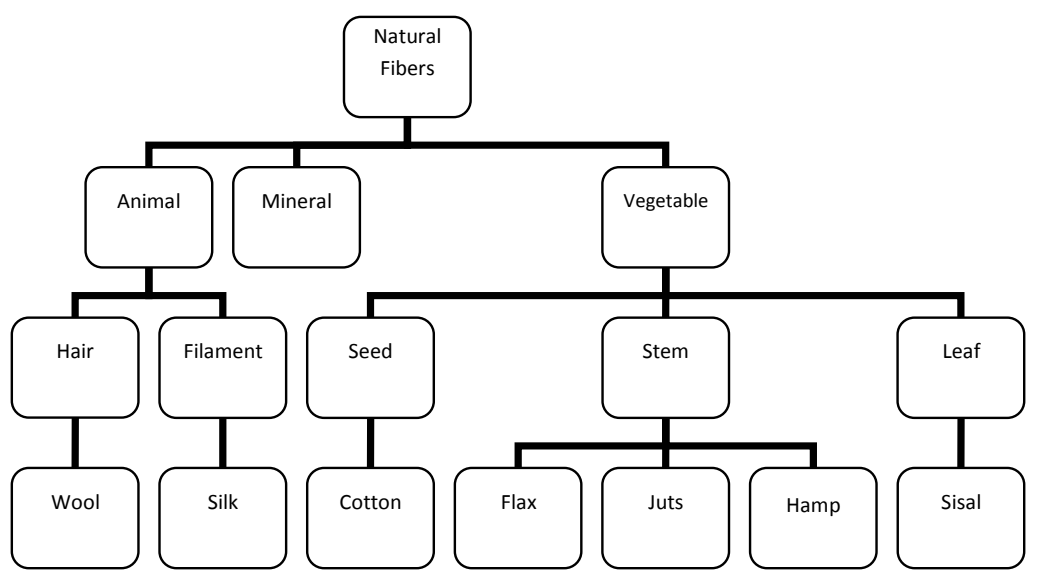

Fig. 1. Natural fibers- partial classification. 
TABLE 1. Components of cotton fiber.

\begin{tabular}{|c|c|}
\hline Cellulose & 85.5 \\
\hline Oil and Wax & 0.5 \\
\hline Protein, Pectoses and Coloring matter & 5 \\
\hline Mineral matter & 1.0 \\
\hline Moisture & 8.0 \\
\hline
\end{tabular}

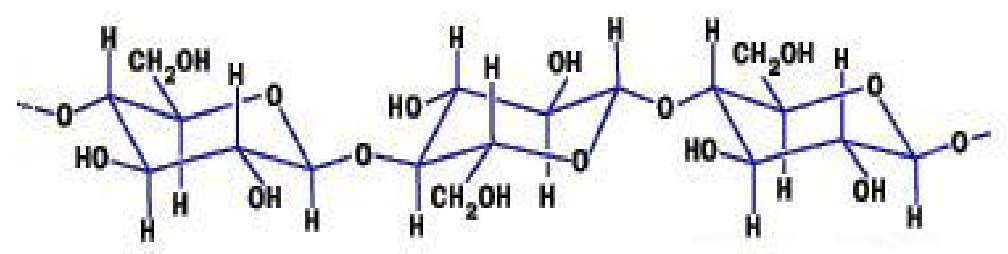

Fig. 2. Chemical structure of cellulose.

The chemical reactivity of cellulose fibers is related to the hydroxyl groups $(\mathrm{OH})$ of the glucose unit. These groups react with moisture, dyes, and some finishes. Chlorine bleaches break the molecular chain of the cellulose by attacking the oxygen atom between the two ring units or within the ring, rupturing the chain or ring. The cellulose molecule is a long, linear chain of glucose units. The chain length affects fiber strength [9].

Fiber properties:

Physical Properties

Color

Cotton is available in a range of colors. Naturally creamy white is highly desirable because it can be dyed or printed $[10,11]$.

Tensile strength

Cotton fiber is relatively strong due to the intrinsic structure of layers of crisscrossed, minute, spiraled fibrils that compose the fiber cell [10].

\section{Heat conductivity}

Heat conductivity of cotton fiber is low and the looser the cotton fiber mass, the lower the conductivity. This property is used for manufacturing cotton wadding. Cotton fibers in dry condition present low electrical condition and thus could be used as an insulator. This electrical conduction increases with humidity [4].

\section{Durability}

Although cellulose has many functional groups, it is surprising that the fiber does not

J. Text. Color. Polym. Sci. 16, No. 2 (2019) actually dissolve in water. But in reality, most of the hydroxyl groups in cellulose are bonded to one another into such a network of hydrogen bonds, their accessibility to water varies according to size and distribution of the crystalline and amorphous regions [12].

\section{Chemical properties}

The action of acids on cotton

Treatment with dilute acids at high temperature will hydrolyze the cellulose to glucose. At lower temperatures and in presence of acid formation of hydrocellulose occurs. Immersion for a short time concentrated nitric acid causes result in shrinkage and an increase in tensile strength as well as affinity for dyestuffs. Longer treatments with nitric acid results in acidification of cellulose to oxy-cellulose, this reaction is favored at higher temperatures [13].

\section{The action of alkalis on cotton}

Mild alkalis have no effect on cellulose at low or at higher temperatures in absence of air. With oxygen present, oxycellulose is produced gradually leading to tendering. A solution of 20 percent sodium hydroxide is used to mercerize cotton, making it stronger, smoother, and hard acquiring a greater affinity for dyes [14].

\section{Effect of organic solvents}

Cotton fiber is insoluble in most organic solvents; it dissolves in few complex solutions, such as cuprammoniom. Dry cleaning solvents do not have any deleterious effect [15]. 


\section{Effect of light}

Cotton fibers oxidize, become yellow and lose strength by exposure to sunlight for a longer period. Cotton fabrics should therefore be shaded from direct sun light [16].

\section{Affinity for dyes}

Cotton has high affinity for dyes. It is dyed with vat azoic and reactive dyes. Good color fastness is possible, but under specific condition [17].

\section{Thermal properties}

Cotton burns readily with a small of burning paper. Exposure to a temperature of $150{ }^{\circ} \mathrm{C}$ in dry condition results in gradual decomposition of take fiber. Higher temperature $250^{\circ} \mathrm{C}$ will cause rapid deterioration. Normal exposure to heat encountered in routine care and processing will not damage cotton. Finishes, such as starch or durable press, increase the tendency to scorch [10].

\section{Synthetic fibers}

Synthetic fibers are defined by the International Organization for Standardization (ISO) as fibers manufactured from polymers built up from chemical elements or compounds $[18,19]$.

\section{Polyester}

polyester, dominates the world of synthetic fibers industry. They are inexpensive, easily produced from petrochemical sources, and have a desirable range of physical properties. They are strong, lightweight, easily dryable and wrinkle-resistant, and have very good wash-wear properties [18].

\section{Chemical Structure}

Polyester is a polymer produced by reaction between smaller molecules, in which the linkage of these molecules occurs through the formation of ester groups (-COO-) by condensation reaction [20]. Polyester (e.g. Terylene) is obtained by polymerizing the dimethyl ester of unsubstituted terephthalic acid with ethylene glycol [21].

\section{Fiber Properties \\ Physical properties \\ Color}

The length and diameter of polyester could be controlled for different end uses. The fiber is partially transparent white or off-white in color.

\section{Tensile strength}

The strength, or tenacity, of polyester varies with the type of fiber, however, as a general category; polyester would be considered a relatively strong fiber. Its strength is not affected by moisture. Regular filaments have a breaking tenacity of 4-7 g/d, high-tenacity filaments are rated at $6.3-9.5 \mathrm{~g} / \mathrm{d}[10]$.

\section{Heat conductivity}

Polyester fabrics possess good heat conductivity, it would be warmer than if made of cotton. This is attributed to its deceased absorbency [17].

\section{Chemical properties}

The action of acids

Polyester fibers are resistant to acids concentrated solutions of sulfuric acid at high temperatures cause degradation of the fabrics [22].

The action of alkalis

Polyester fabrics are resistant to weak alkalis while less resistant to strong alkalis. This resistance is reduced with increased temperature [23].

\section{Effect of organic solvents}

Polyester fibers show high resistance to most of the common organic solvents like acetone, dioxin, ether, methyl alcohol and carbon tetrachloride. The ranges of chemicals that will dissolve polyester fiber at normal or moderate temperatures are limited, and the only chemicals -which as a class- will do this are phenols. Most phenols will swell or dissolve polyester fiber depending on the temperature and concentration used. Hot m-cresol destroys the fiber and mixtures of phenol in trichloroethane dissolve the fiber [23].

\section{Effect of light}

Polyester fabrics are resistant to sun light degradation, consequently they are suitable for outdoor application. Prolonged exposure to sun light causes deterioration of fibers [24].

\section{Affinity for dyes}

Polyester fiber is difficult to dye since there are no chemical groups in the polyester molecule that will unite with dyestuffs and the molecules are packed so, there is no space to wedge in dye molecules. Also, the interchain forces are so strong that high temperatures are required to loose them so dye molecules can enter. In darker shades, expensive dye assistants or carriers are needed and these must be removed from the fiber after dyeing to preserve light fastness. Only by use of disperse, azoic and pigment dyes at high temperature. Some polyester is modified to take basic dyes [25, 26]. 


\section{Thermal properties}

Polyester fibers are thermally stable. The tenacity of all thermoplastic fibers was found to decrease and their elongation was increased at temperature of $150{ }^{\circ} \mathrm{C}[5]$.

\section{Polyester Microfiber}

There has been a trend to produce finer synthetic filament fibers, and consequently various microfibers have been developed with new fiber spinning techniques to reduce thickness and alter the cross section shape. Microfiber fabrics have enhanced drapeability, luster, softness, bulkiness, and smoothness, and also high tactile aesthetics and high water absorption and chemical adsorption properties.

\section{Polyamide Fiber}

Polyamides are one of the most important synthetic fabrics they are usually known as nylons. Any nylon must contain atoms of carbon, hydrogen, Oxygen and nitrogen. The difference nylons are named depending on the number of carbon atoms percent in the molecule of starting materials .Thus hexamethylene diamine (contain six carbon atom per molecule) and adipic acid contain six carbon atom per molecule) give nylon 66. Amino carpoic acid (contain six carbon atom per molecule) give nylon 6 [23].

\section{Polyamide Structure:}

The most wide-spread polyamides in use and production are nylon 6 and nylon 66 . The essential structural similarities and differences between nylon 6 and 66 are illustrated in Scheme [24].<smiles>CCNC(=O)CCCCCNC(=O)CCCCCNC(C)=O</smiles><smiles>CC(C)NC(=O)CCCCCCNC(=O)CCCCCNC(=O)CN</smiles>

Fig. 3. Comparison between nylon 6 (above) and nylon 66 (blow).

Polyamide properties:

Polyamide has specific gravity lower than most other fabrics so it can be made into very light, sheer fabrics of good strength. Excellent strength of nylon led to its use not only in for tire cords but also for a variety of industrial items. Its abrasion resistance is superior , being four to five times that of wool.

Textile printing:

Textile printing could be defined as the art of producing colored designs onto fabric surfaces [27].

\section{Printing styles}

Direct printing

\section{Discharge printing}

In discharge printing, the fabric is first dyed to a solid shade and then printed with a paste containing chemicals able of destroying the color could be achieved during the next steaming process. This allows printing of white designs on a ground color could be achieved [19]. If the paste contains dyes resistant to the discharging agent used, these dyes, named as illuminating colors, will color the printed areas [19].

\section{Resist printing}

Resist printing block color absorption during fabric dyeing or during color application ${ }^{(11)}$, the fabric is treated first with a composition that resists both dye penetration and fixation. During dyeing process, the areas free of resisting agent could be colored [19].

\section{Printing Methods: \\ Block printing}

Block printing is considered the oldest technique for textile decoration. It is a slow and expensive technique. A block is craved with a pattern; subsequently the block is dipped in the dye paste and stamped on fabrics [11].

\section{Stencil printing}

In stencil printing a pattern is cut from a special waxed paper or thin metal sheet for every. Dye solution or paste, is applied by hand with a brush or by spraying with an air gun [11].

\section{Roller printing}

The fabric is drawn around a metal or cylinder during printing. The engraved printing roller is etched with the design for each color in the print. A different printing roller applies each color. They revolve in a small color trough, pick up the dye paste, and deposit it on the rollers. A doctor blade scrapes off excess color so that only the engraved portions are filled with dye when it contact with the fabric [11].

\section{Screen printing}

Screen printing is sample and versatile, yet simple, process. A mesh is coated with a compound 
that seals all openings in the screen opening and prevents the dye paste from moving through the screen, except in the areas to be printed according to the required design. One screen is used for every color. Squeegee is used to force the paste though the opening of the screen [11].

\section{Flat screen printing}

The screen is partitioned on the fabrics to print and the color is applied, and the screen is moved to a new position. The process is repeated with all the fabric is printed [11].

\section{Rotary screen printing}

In rotary screen printing, colored paste is forced through the open areas of a cylindrical printing screen that rotates as the fabric moves beneath it. The paste collects under the stationary squeegee, which forces it out through the holes in the rotating screen [19].

\section{Transfer printing:}

Heat transfer printing is a one of most major fabric printing methods. Heat transfer printing technique involves transfer of color from one surface to another, usually from paper to textile $[27,28]$. In textile industry, transfer printing implies the sublimation of dyes from printed design on paper at elevated temperature, the dye vapors are subsequently absorbed by the synthetic fabrics [19]. In the last years, transfer printing has evoked considerable academic and industrial the advent and increased production of synthetic polymer fabrics is a main reason for that. The main transfer printing processes can be classified in to four basic systems, with varying success in application as follows:

\section{Melt transfer system}

In this system, paper is used as the carrier of design, then subsequently transferring the pattern from the paper on to the textile material. The color (usually pigment) and its binder melted by the application of heat while the paper is in contact with the fabric. Thus, the design is transferred to the fabric and solidifies on cooling. The process is now widely used in T-shirts, and printing of labels and badges.

\section{Film release system}

In this system a plastic layer is brought in to contact with the fabric using heat and pressure so that the adhesive forces are developed and the film is transferred to the fabric and the paper can be peeled away leaving the design stuck onto the fabric [29].

\section{Wet heat transfer printing}

The wet heat transfer printing systems utilize heat in a wet atmosphere to facilitate the sublimation of the dye pattern. There are two major systems Fastran and Dewprint. The Fastran process is well suited for cotton and wool blends, as well as all nylon fabrics. The goods are padded with an aqueous bath containing Fastran powder which contains sulfamic acid, gum derivatives that hold a moisture film over the material during transfer and surfactant derivates that facilitate high level dye absorption. After the fabric is prewetted by the padding process with a solution of the powder, the transfer print paper is placed over it and a silicone rubber sheet covers it. The print sandwich is then placed in a steam or dielectric heated press where the heat converts the water to steam. The print vaporizes and migrates from the paper to the fabric. The Dew-print process is well suited for cotton goods and may be effectively used for wool, wool blends, nylon and acrylic fabrics. The material is padded with a proprietary emulsion, which aids the dye transfer from paper to fabric. It is then passed along with the printed transfer paper over a cylinder heated at a lower temperature than is used for dry heat transfer printing. The fabric is washed to remove the emulsion assistant and is dried [30].

\section{Vapor-Phase (dry transfer printing)}

Heat transfer printing comprises two steps, the former step involves printing of color design on paper support using the conventional paper printing techniques and specially formulated inks containing sublimely disperse dyes. The latter entails transfer of the design front the paper to the fabric on transfer printing machines at temperatures as high as $180-200^{\circ} \mathrm{C}$. The printed paper is brought into close tact with the synthetic fabric under pressure and at high temperatures, two things happened, dyes sublime and the fabric fibers approach softening point. At this situation, the vapors are absorbed by the fabric and it is completely transferred to it.

\section{Batik printing}

Batik is generally a hand process in which hot wax is applied to a fabric in the form of a design. When the wax has set or hardened, the fabric is piece-dyed. Dye penetration is prevented in the wax covered portions. Colors are built up by piecedyeing light colors first, waxing new portions, and re-dyeing until the design is complete. The wax is later removed by solvent or by boiling [11]. 

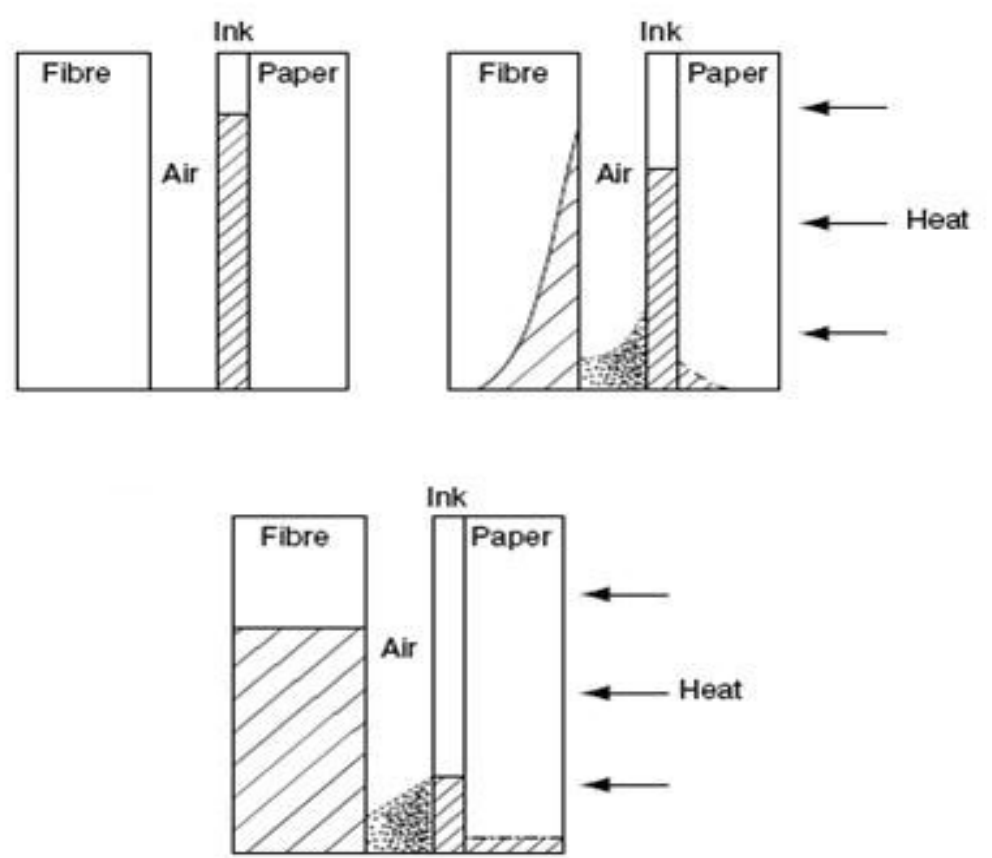

Fig. 4. Dye transfer during vapor phase printing.

Foil print:

In foil printing a special adhesive is applied to the fabric by a flatbed or rotary screen. The fabric is dyed and partially cured. The foil combines a thin polyester film with a heat-sensitive release coating, a very thin layer of aluminum, and clear or tinted lacquer. The metallic foil is heated on a heat-transfer press and foil bonds only where the adhesive pattern exists on the fabric.

\section{Digital printing}

In digital (ink-jet) printing, micro drops of colored liquid ink are applied through tiny nozzles onto the surface of precise points. Computers control the specific color ink jet, amount of ink, and location of the micro drops. Digital printers operate with four basic colors (yellow, magenta, cyan, and black) which pose unique challenges in mixing color for textiles.

There are several types of digital printers, including continuous ink jet (CIJ) and drop on demand (DOD).

\section{Disperse Dyes}

The previous phase of innovation in the field of disperse dyes derived from heterocyclic compounds.which has revolved around finding replacements for red and blue anthraquinon of textile colorants, is over. However, research continues unabated in response to the increased demands placed on disperse dyes as a result of the textile coloration industry seeking to add J. Text. Color. Polym. Sci. 16, No. 2 (2019) ling to the trends for finer substrate filaments, greater use of blends and finishing treatments, more exacting fastness specifications as well as more demanding application techniques. Literature, in the last 20 years have witnessed considerable growth in the amount of information published pertaining to the synthesis, properties and application of hetarylazo dyes. Prior to the start of the last decade ,much of the little material available on disperse dyes from five-membered, six memberd and condensed heterocyclic azo compounds were fragmentary, now modern comprehensive studies have been published ,furnishing data for many of these types. Such information has fleshed out extended knowledge of heterocyclic disperse dyes and helped to explain the commercial success of particular as well as introducing new heterocyclic of either a slightly modified or radically different nature. Statements on the future of disperse dye research made at the end 1990's turned equally true today. Textile dye chemists are still looking for brighter, more cost-effective colorants which can add value to substrate as well as meet the ever-increasing demands placed on them by consumers, dyers and legislators. Also, the promising non-textile applications of disperse dyes, drawn much interest in a wide range of disciplines and businesses. Undoubtly, research to drive hetarylozo dyes and heterocyclic disperse dyes, whether approached from an industrial 
or academic perspectives, will be the subject of investigation for years to come. However, there has been a considerable growth in the volume of data reported outside of the patent literature. Excellent reviews concerning heterocyclic azo dyes exist but were published some time ago by Towns in 1999. The author reviewed the materials appeared in the last decade and discussed the developments concerning azoles disperse dyes in the field of preparation, properties and application, examples are given below:

This is 2-cyano-3-(5-amino-3-methyl-pyrazole4-yl)azo-4,6-disubstitutedthieno[2,3]pyr-idines. These dyes showed good fastness, properties on polyester fabrics [30].<smiles>[R]C1=CC([R])=C2C1=C(/N=N\c1c(C)n[nH]c1N)Sc1nc([R])c2[nH]1</smiles>

Synthesis of 4-amino-1Hbenzo [4, 5]imidazo [1,2-a]pyrimidin-2-one (I). These dyes give an excellent yield [31].<smiles>[R]c1ccc(N=Nc2c(N)n3c(nc4ccccc43)[nH]c2=O)cc1</smiles>

This is newly synthesized azo dyes using photo induced birefringence experiment [9-12].

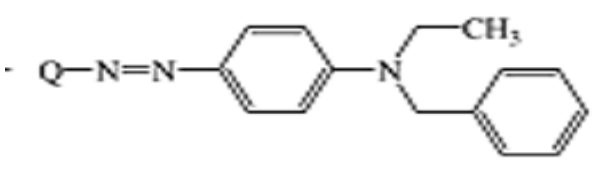

These is synthesis of some novel monoazo disperse dyes. These dyes have been found to give bright yellow to maroon color shade with very good depth and levelness on fabric [9-12].

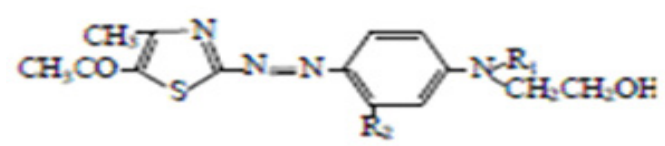

4-[(2-Amino-4-methylthiazol-5-yl)diazenyl] benzenesul-fonamide.<smiles>Cc1nc(N)sc1N=Nc1ccc(S(N)(=O)=O)cc1</smiles>

4-[(2-Amino-4-methylthiazol-5-yl) diazenyl)$\mathrm{N}$-(pyridin-2-yl]benzene sulfonamide.

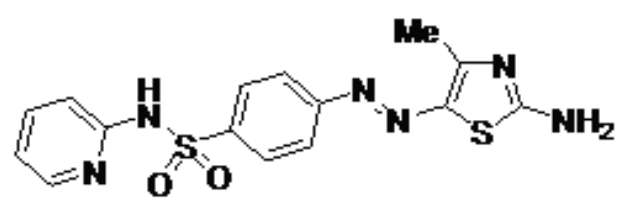

4-[(2-Amino-4-methylthiazol-5-yl)diazenyl]$\mathrm{N}$-(pyrimidin -2-yl) benzenesulfonamid)

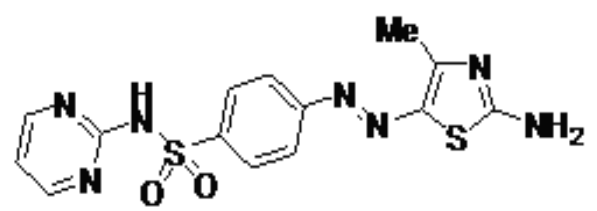

$4-\{[4-$ Methyl-2-(4-(piperidin-1-yl) benzylideneamino]thiazol-5-yl)diazenyl $\}$ benzene sulfonamide<smiles>Cc1nc(/N=C/c2ccc(N3CCCCC3)cc2)sc1N=Nc1ccc(S(N)(=O)=O)cc1</smiles>

$4-\{[4-$ Methyl-2-(4-(piperidin-1-yl) benzylideneamino) thiazol-5-yl] diazenyl $\}-\mathrm{N}$ (pyridin-2-yl)benzene sulfon -amide

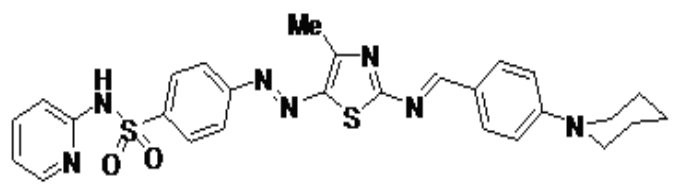

$4-\{[2-(4-($ D i m e t h y 1 a m i n o ) benzylideneamino)-4-methylthiazol-5-yl] diazenyl benzenesulfonamide .

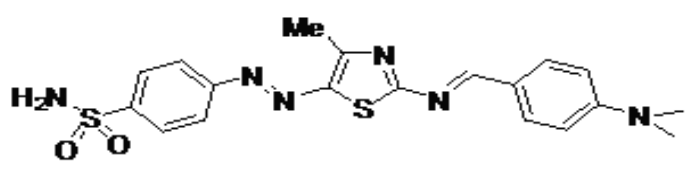

J. Text. Color. Polym. Sci. 16, No. 2 (2019) 
$4-\{[2-(4-($ D i m e th y 1 a m i no $)$ benzylideneamino)-4-methyl thiazol-5-yl)d iazenyl]-N-(pyridin-2-yl $\}$ benzene sulfonamide..

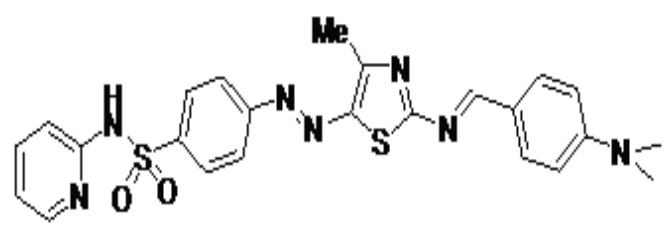

$4-\{[2-(4-($ D i m e t h y 1 a m i n o $)$ benzylideneamino)-4-methyl thiazol-5-yl) diazenyl]-N-(pyrimidin-2-yl) benzene${ }_{N}^{N}$

4-\{4-Methyl-2-[2-(1-phenylethylidene) hydrazinyl)thiazol-5-yl)diazenyl] benzenesulfonamide.

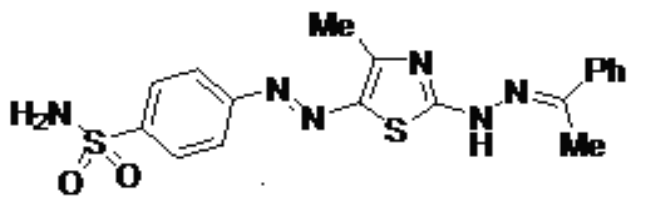

4-\{4-Methyl-2-[2-(1-phenylethylidene) hydrazinyl)thiazol-5-yl]diazenyl $\}-\mathrm{N}$-(pyridin-2ylbenzene)sulfonamide).

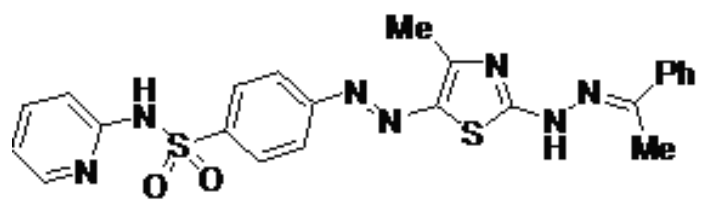

\section{References}

1. P.H.Greaves, B.P.Saville, "Microscopy of textile fibers", 1st Edition, Bios Scientific, London, P.1(1995).

2. I.Emery, "The primary structure of fabric",1st Edition, waston-Guptill publications, washing ton, P.4 (1995).

3. F.Sadov, M.Korchagin and A.Matetsky, "Chemical technology of fibrous material", Mir, Moscow,P11(1973).

J. Text. Color. Polym. Sci. 16, No. 2 (2019)
4. G.EL-Nouby, H.A.Azzam, "Spinning technology", 1st Edition, Industrial Education College Textile Technology Dept., P.2 (2003).

5. P. R. Lord, "Hand book of yarn production science and technology"1st Edition, Wood head publishing limited, Cambridge, England, P7-8 (2003).

6. W. S. Murphy, Elements of fiber science, 1st Edition, Aphishek publications, Chandigrph, India, P.73(2002).

7. S. R. Trotman and E. R. Trotman, The bleaching, dyeing, and chemical technology of textile fibers, 2nd Edition, Charles Griffin, and company limited, London, P.98( 1946).

8. R. H. Peters, Textile chemistry, volume1, Elsevier publishing company, New York, P.177(1963).

9. S. J. Kadolph , A. L. Langford, "Textiles", 8th Edition, Prentice-Hall, Inc., P130-150 (1998).

10.H. Rinehart, "Essentials of textiles", 4th Edition, Winston, Inc., Orlando, Florida, P.66-68 (1998).

11. Sara J. Kadolph, “Textiles” 10th Edition, PrenticeHall, P45.

12.J.R.Aspland, "Textile dyeing and coloration", American Association of Textile chemists and colorists, USA.

13.E. R. Trotman, "Dyeing and Chemical Technology of textile fiber", 6th Edition, Edward Arnold Publication, London, P.28 (1990).

14.R. T.O .Connor, "Instrumental Analysis of cotton cellulose and Modified Cotton Cellulose", Vol.3, Marcel Dekker, Inc., New York, P.160 (1972).

15.M. Harris, "Hand Book of Textile Fibers", 1st Edition, Textile Book Publishers, Inc., New York, P.67 (1954).

16.S. Marshall, A. Todd, Trans.Faraday Soc.,49,77 (1953).

17. M. L. Joseph, "Essentials of textiles", 2nd Edition, Holt, Rinehert and Winston, New York, P. 178-180 (1980).

18.J.E.Mcintyre, "Synthetic fibers: nylon, polyester, acrylic, polyolefin”, Wood head publishing limited, Cambridge, England.

19. Arthur D Broadbent, "Basic Principles of Textile Coloration, Society of Dyers and Colourists P.504 (2001).

20.M. Harris, "Hand Book of Textiles", 2nd Edition, 
Pergamon press Ltd. Oxford and Pergamon press Inc., New York, (1974).

21.R. W. Moncrieff, "Man-made Fibres”, Heywood and Company, London, P361 (1963).

22.P. G. Tortora, B. J. Collier, "Understanding Textiles", 5th Edition, Prentice Hall, Inc., New York, P. 95-97(1997).

23.J. Gordoncook, "Hand Book of Textiles Fibers", 4th Edition, Merrow Publishing Co., England, P. 354(1968).

24.I. B. Wingate, "Textile Fabrics and their selection", 7th Edition, Prentice-Hall, Inc., Engle Wood Cliffs, P. 350 (1976).

25.E. R. Trotman ,'Dyeing and Chemical Technology of Textile Fibers", 3rd Edition, P. 90(1963).

26.D. M. Nunn, W. Beckmann, D. Blackburn Land and R. Broadhurst, "The dyeing of synthetic Polyester and Acetate Fiber", 1st Edition, Dyer Co., Publication Trust, P. 136(1979).

27.M. S. Leon, JTATM 3(3), 1(2003).

28.P. Mirko, US patent 20050117956 (2005).

29. G. Gherzi, Melliand Textilberichte, 78(1), 75 (1997).

30.I. D. Rattee, J. Soc, Dyers and colourists, 93,190 (1977).

31. E. Aktan, N. Ertan, T. Uyar, Journal of Molecular Structure, Volume 1060, 215-222(2014).

(Received 19/8/2019; accepted 26/8/2019) 


\section{تكنولوجيا الطباعة على ألياف النسيج مديحة القاشوطي ، شيماء الحداد * ، كوثر عبد الظاهر \\ قسم الصباغة والطباعة والمو اد الوسيطة ، شعبة بحوث الصناعات النسيجية ، المركز القومي للبحوث

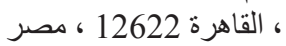

\footnotetext{
تم تطبيق عجينة الطباعة التي تحتوي على الأصباغ على الأقشة كطباعة مباثشرة ، وبالتالي التثبيت بالبخار تليها الغسيل

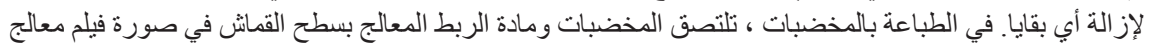

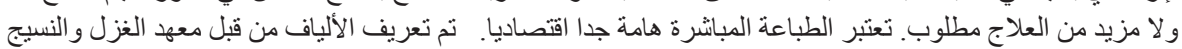

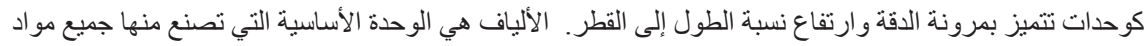
النسيج. يتم تصنيع السلع النسيجية من مو اد ليفية قد نكون إما من أصل طبية الصيعي أو من صنع الإنسان.
} 